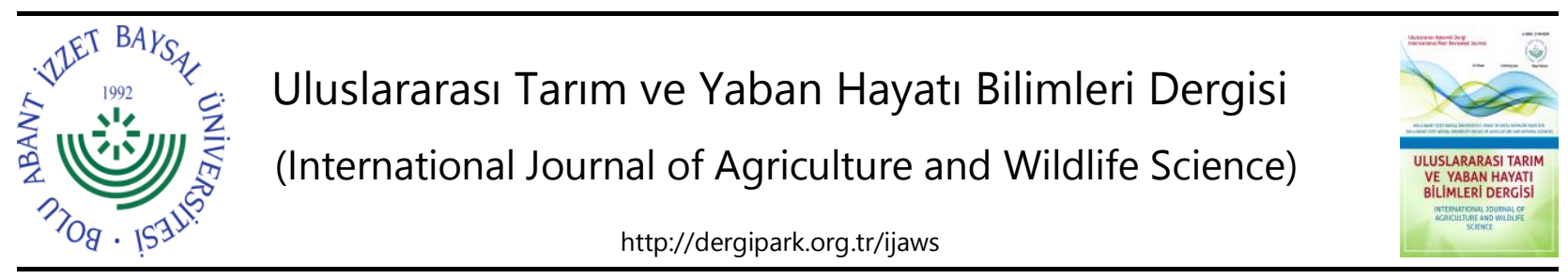

Araştırma Makalesi

\title{
Bolu ili Ekolojik Koşullarında Scarlet, Superchief, Jeromine, Pink Layd Rosy Glow Elma (Malus communis L.) Çeşitlerinin Adaptasyon Kabiliyetlerinin Belirlenmesi
}

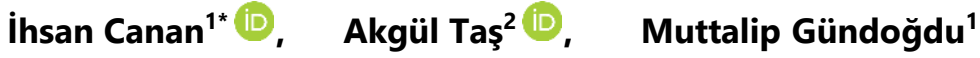 \\ ${ }^{1}$ Bolu Abant İzzet Baysal Üniversitesi, Ziraat Fakültesi, Bahçe Bitkileri Bölümü, Bolu \\ ${ }^{2}$ Bolu Abant İzzet Baysal Üniversitesi, Seben Meslek Yüksekokulu, Bitkisel ve Hayvansal Üretim Bölümü, Bolu
}

Geliş tarihi (Received): 04.12.2020Ｋabul tarihi (Accepted): 19.03.2021

\begin{abstract}
Anahtar kelimeler:
Bolu, Elma, adaptasyon, fidan, don zararı

*Sorumlu yazar

ihsancanan@gmail.com

Özet. Bu çalışma, 2016 ve 2018 yıllarında Bolu ili ekolojik koşullarında yetiştirilen çeşitlerin adaptasyonunun belirlenmesi amacıyla yürütülmüştür. Elma fidanlarında adaptasyon kabiliyetini tespit etmek amacıyla bazı parametreler belirlenmiş ve çeşitlerin gelişimi ile ilgili gözlemler yapılmıştır. Çalışmada yapılan ölçümlerde çeşitlerin ağaç boyu $114.80 \mathrm{~cm}$ (Superchief) ile 135.80 cm (Jeromine) arasında değişmiştir. Kısa dal uzunluğu en az olan çeşit Superchief $(39.63 \mathrm{~cm})$ iken kısa dalları en uzun olan çeşit Jeromine $(50.10 \mathrm{~cm})$ olarak belirlenmiştir. Çalışmada en kısa uzun dal uzunluğuna sahip çeşit Pink Lady-Rosy Glow $(59.10 \mathrm{~cm})$ iken en uzun uzun dala sahip çeşit Superchief $(91.99 \mathrm{~cm})$ olmuştur. Gövde çapı en az olan çeşit Scarlet $(5.45 \mathrm{~cm})$, gövdesi en kalın olan çeşit Pink Lady-Rosy Glow'dur (6.72cm). Dal sayısı en az olan çeşit Superchief (3.67adet)tir ve Scarlet en yüksek (7.40 adet) olarak belirlenmiştir. En düşük dal çapına sahip çeşit Pink Lady-Rosy Glow $(2.05 \mathrm{~cm})$ olarak kaydedilirken en fazla dal çapına sahip çeşit Superchief $(3.51 \mathrm{~cm})$ olmuştur. Don zararına en az maruz kalan çeşit Jeromine (\%14.50) karşı şekilde en fazla don zararına maruz kalan çeşit Scarlet (\%59.50) olarak belirlenmiştir. Çalışma sonucunda Jeromine ve Pink Lady - Rosy Glow çeşitleri hızlı gelişimi ve diğer birçok gelişim özellikleri açısından diğer çeşitlerden iyi olması ve don zararına görece daha dayanıklı olmaları nedeniyle Bolu'da elma yetiştiriciliği için tavsiye edilebilecek çeşitler olarak değerlendirilmiştir.
\end{abstract}

\section{Determination of Seedling Adaptations of Scarlet, Superchief, Jeromine, Pink Layd Rosy Glow Apple (Malus communis L.) Cultivars Grown in Bolu Ecological Conditions}

\section{Keywords:}

Bolu, apple, adaptation, seedling, frost damage
Abstract. This study was carried out to determine the adaptation of cultivars grown in Bolu ecological conditions between 2016 and 2018. In order to determine the adaptation ability in apple seedlings, some parameters were determined and observations related to the development of the varieties were made. The tree length of cultivars varied between $114.80 \mathrm{~cm}$ (Superchief) and $135.80 \mathrm{~cm}$ (Jeromine). The shortest branch length is Superchief $(39.63 \mathrm{~cm})$, while the shortest branch length is determined as Jeromine $(50.10 \mathrm{~cm})$. While the shortest long branch length was Pink Lady-Rosy Glow $(59.10 \mathrm{~cm})$, the longest long branch was Superchief $(91.99 \mathrm{~cm})$. While the scarlet $(5.45 \mathrm{~cm})$ with the lowest stem diameter is the thickest, Pink Lady-Rosy Glow $(6.72 \mathrm{~cm})$ has the thickest stem. While the lowest branch number is Superchief (3.67 pcs), Scarlet has been determined as the highest $(7.40 \mathrm{pcs})$. Pink Lady-Rosy Glow $(2.05 \mathrm{~cm})$ has the lowest branch diameter, while Superchief $(3.51 \mathrm{~cm})$ has the highest branch diameter. The least exposed type of frost damage was Jeromine (14.50\%), while the most exposed type of frost damage was determined as Scarlet (59.50\%). As a result of the study, Jeromine and Pink Lady - Rosy Glow varieties were evaluated as the ones that can be recommended for apple cultivation in Bolu because they are better than other varieties in terms of their rapid development and many other development features and they are relatively more resistant to frost damage. 


\section{GíRiş}

Elma (Malus communis L.) Dünya'da ve ülkemizde tarımı yapılan meyve türleri arasında ilk sıralarda gelmektedir (Güleryüz ve Ercisli, 1995). Ilıman iklim meyve türleri arasında yer alan elma, Rosales takımının Rosaceae familyası içerisinde bulunan Malus cinsine aittir. Ülkemiz çoğu tarım ürününde olduğu gibi meyvecilik yönünden de gen merkezi durumundadır, birçok meyvenin tür ve çeşidi bakımından oldukça zengin bir yapıya sahiptir (Özbek, 1978; Edizer ve Bekar, 2007). Elma ayrıca Anadolu, Avrupa, Çin, Himalaya, Japonya, Kore ve Kuzey Amerika gibi farklı gen merkezlerine yayılım göstermiş ve 48 türünün mevcut olduğu bildirilmiştir (Özbek, 1978a; Dziubiak, 2004; Ercisli, 2004; Edizer ve Bekar, 2007). Elma, meyve kalitesi ve Türkiye'nin birçok bölgesinde yetiştirilebilmesi nedeniyle tüketiciler tarafından yıl boyunca tercih edilmekte ve tüketilmektedir (Ağlar ve Öztürk, 2018).

İklim toleransının yüksek olması nedeniyle birçok yerde kolay yetişen bir meyve olan elmayı, tüketici tarafından talep görmesi ve uzun süre saklanabilmesi yetiştiricilik açısından daha cazip hale getirmektedir (Çorumlu, 2010).

Dünya elma üretiminin yarıdan fazlası Asya ülkelerince yapılmaktadır. Gen merkezi olmasının getirdiği avantajlardan başka, ılıman iklim kuşağındaki kara alanlarının fazla olması da Asya kıtasına elma üretiminde avantaj sağlamaktadır. Amerika kıtası, Asya ve Avrupa' ya göre daha düşük paya sahip olmakla beraber elma üretim miktarı en fazla olan üçüncü kıtadır (Öztürk ve ark., 2011).

FAO (2019)'e göre, dünya elma üretimi toplam 83.139.326 ton'dur. Bu üretim içinde Çin 41.391 .500 ton üretim ile 1. sırada yer alırken, ABD 5.173.670 ton'luk üretim ile 2. ve Türkiye 3.032.164 ton ile 3. sırada yer almaktadır.

Ülkemizde üretimin büyük bir kısmı halen geleneksel metotlarla yapılmaktadır. Son yıllarda plantasyonlar, yoğun yetiştiricilik metotlarına uygun olarak tesis edilmekte, yeni çeşitlerle modern yetiştiriciliğe doğru yavaş da olsa bir dönüşüm yaşanmaktadır. Türkiye' de işletmelerin küçük ölçekli olması, yoğun üretim metotlarına geçiş hızını azaltmaktadır. Ülkemizde hemen hemen tüm illerde elma yetiştiriciliği yapılmaktadır. Ticari olarak elma üretimi yapan iller; Isparta, Karaman, Niğde, Denizli ve Antalya'dır (TÜiK, 2019).

Elma üretimimizin dünya üretimine kıyasla iyi bir oranda olmasına rağmen ihracat oranı oldukça azdır. Bu da üretim yerleri ekolojik şartlarına uygun çeşit ve adaptasyon çalışmalarının azlığı ve bundan kaynaklı standardizasyon, pazarlama sorunları, verimli-kaliteli ürün yetersizliği, modern bahçe tesisi azlığı, yenilikgelişmelerin takipsizliğinden kaynaklanmaktadır.

Ekolojiye uygun tür ve türlere ait çeşitlerin tespiti, üretimin, sürdürülebilir ve ekonomik olması bakımından son derece önemlidir (Eskimez ve ark., 2020). Bu çalışmada, Bolu ili ekolojik koşullarında yetiştirilen çeşitlerin adaptasyonunun belirlenmesi için elma fidanlarında adaptasyon kabiliyetini tespit etmek ve belirlenmiş bazı parametrelerin ve çeşitlerin gelişimi ile ilgili gözlemlerin yapılması amaçlanmıştır.

\section{MATERYAL VE METOT}

\section{Materyal}

Deneme, 2016-2018 yılları arasında Abant İzzet Baysal Üniversitesi Ziraat Ve Doğa Bilimleri Fakültesi Uygulama Bahçesi'nde sıra arası ve sıra üzeri $3 \times 4 \mathrm{~m}$ aralıklarla dikili elma parselinde yürütülmüştür. Çalışma materyalini 2 yaşlı MM106 üzerine aşılı Scarlet, Superchief, Leromine, Pink Lady Rosy Glow çeşitleri oluşturmaktadır. Çeşitler; ülkemizde oldukça bilinen yaygın olarak değişik bölgelere yeni bahçelerin kurulması için tavsiye edilen ticari değeri olan elma çeşitleridir.

\section{Yöntem}

Çalışmada, daptasyon kabiliyetini tespit amacıyla çeşitlerin gelişimi ile ilgili gözlemler yapılmıştır. Bu amaçla adaptasyon parseline alınan tür ve çeşitlerle kurulu bahçelerdeki fidanlarda kumpas ve şerit metre yardımıyla Şekil 1'de gösterildiği gibi fidan boyu (AB arası) (Bolat, 2011), kısa dal uzunluğu (1), orta dal uzunluğu (2), uzun dal uzunluğu (3), gövde çapı (X) (Bolat, 2011), dal çapı (Y), dal sayısı, yaprak sayısı, yaprak uzunluğu, yaprak eni ölçülmüş (Taş ve ark., 2019) ve don zararından etkilenme durumları (Sürgünlerin kurumuş kısımlarının tüm sürgün uzunluğuna oranı) şu formüle göre kaydedilmiştir: Don zararı $(\%)=$ (Kuruyan kısmın uzunluğu $x$ Sürgünün tüm uzunluğu ${ }^{-1}$ ) x 100. Gövde çapı aşı yerinin $15 \mathrm{~cm}$ üstünden ölçülmüştür (Talluto ve ark., 2008). Fidanlar henüz çok genç yaşta olduğu için fidanlarda Şekil 1'de gösterildiği gibi tepe sürgününden başka sadece üç ana dal mevcuttur. Dal ve sürgün gözlemleri mevcut olan bu üç ana dalda yapılmıştır.

Araştırmanın yürütüldüğü Bolu ilinde 1929-2020 yılları arasında belirlenen ortalama sıcaklık $10.5{ }^{\circ} \mathrm{C}$, maksimum sıcaklık $27.9{ }^{\circ} \mathrm{C}$ (Ağustos), ortalama minimum sıcaklık $-3.6^{\circ} \mathrm{C}$ (Ocak), toplam yağış $549.8 \mathrm{~mm}$ 'dir. 
Canan ve ark., Bolu Ili Ekolojik Koşullarında Scarlet, Superchief, Jeromine, Pink Layd Rosy Glow Elma (Malus communis L.) Çeşitlerinin Adaptasyon Kabiliyetlerinin Belirlenmesi

Ocak Şubat Mart Nisan ve Mayıs aylarında en düşük sıcaklıklar sırasıyla $-31.5,-25.8,-19.8,-11.5$ ve $-2.3^{\circ} \mathrm{C}$ olarak belirtilmiştir (MGM, 2021).

Araştırmanın yürütüldüğü bahçe toprağının fiziksel ve kimyasal özellikleri Tablo 1.'de verilmiştir

Tablo 1. Toprak analiz değerleri (Sönmez ve ark., 2018).

Table 1. Soil analyses values.

\begin{tabular}{|c|c|c|c|c|c|c|c|c|}
\hline $\begin{array}{l}\text { Derinlik } \\
\text { (cm) }\end{array}$ & Tuz & pH & Kireç & Kum & Kil & Silt & $\begin{array}{c}\text { Bünye } \\
\text { Sınıfı }\end{array}$ & $\begin{array}{l}\text { Organik } \\
\text { Madde }\end{array}$ \\
\hline & dS $m^{-1}$ & & & $\%$ & & & & $\%$ \\
\hline $0-20$ & 0.843 & 7.99 & 6.68 & 30 & 6 & 68 & Siltli Tın & 3.99 \\
\hline \multirow[t]{3}{*}{$20-40$} & 0.636 & 7.99 & 8.49 & 30 & 8 & 62 & Siltli Tın & 3.22 \\
\hline & Fosfor & Potasyum & Kalsiyum & Magnezyum & Sodyum & & & \\
\hline & & & $\mathrm{mg} \mathrm{kg}^{-1}$ & & & & & \\
\hline $0-20$ & 26.9 & 368.6 & 10780 & 178.6 & 53.46 & & & \\
\hline \multirow[t]{3}{*}{$20-40$} & 19.4 & 379.2 & 10560 & 173.6 & 55.25 & & & \\
\hline & $\mathbf{F e}$ & $\mathbf{Z n}$ & Mn & $\mathrm{Cu}$ & & & & \\
\hline & \multicolumn{4}{|c|}{$\mathrm{mg} \mathrm{kg}^{-1}$} & & & & \\
\hline $0-20$ & 24.30 & 0.36 & 2.44 & 52.12 & & & & \\
\hline $20-40$ & 28.26 & 0.40 & 2.72 & 50.48 & & & & \\
\hline
\end{tabular}

Çalışma tesadüf parselleri deneme desenine göre 5 tekerrürlü ve her tekerrürde 10 bitki olacak şekilde planlanmış ve yürütülmüştür. Veriler DUNCAN çoklu karşılaştırma testine tabi tutulmuş ve istatistiki değerlendirme yapılmıştır. İstatistikler için R Studio paket programı kullanılmıştır (Team, 2013).

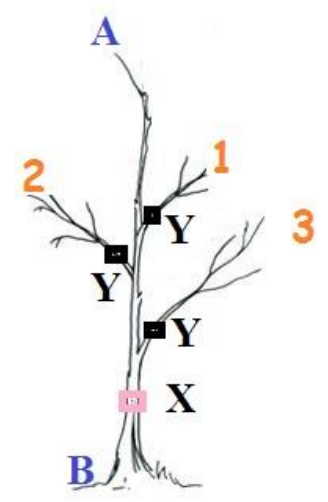

Şekil 1. Fidanlarda yapılan ölçümlerin yerleri.

Figure 1. Places of measurements on seedlings.

\section{BULGULAR VE TARTIŞMA}

Çalışmada yapılan ölçümlerde çeşitlerin fidan boyu şu şekilde tespit edilmiştir: Scarlet $122.80 \mathrm{~cm}$, Superchief $114.80 \mathrm{~cm}$, Jeromine $135.80 \mathrm{~cm}$, Pink Lady Rosy Glow $130.40 \mathrm{~cm}$. En kısa çeşit Superchief $(114.80 \mathrm{~cm})$ iken en uzun çeşit Jeromine $(135.80 \mathrm{~cm})$ olmuştur. Aralarındaki $16 \mathrm{~cm}$ 'lik fark istatistiki olarak önemli bulunmamıştır (Tablo 2). Talluto ve ark. (2008) MM106 ve M9 anacı üzerine aşılı 5 yaşlı pink lady elma çeşidinde fidan boyunu sırasıyla 2.19 ve 1.97 m olarak bildirmiştir. Özongun ve ark. (2014), MM106 anacı üzerine aşılı 7 yaşı Scarlet çeşidinin boyunun ortalama $2.50 \mathrm{~m}$ olduğunu bildirmiştir. Ağaç boyundaki bu düşüşün sebebinin çalışmamızdaki fidanların henüz 3 yaşında olması ve çalışmanın yapıldığı yıllarda oluşan sert ilkbahar koşulları olduğu düşünülmektedir.

Çeşitlerin kısa dal uzunlukları sırasıyla Scarlet $48.44 \mathrm{~cm}$, Superchief $39.63 \mathrm{~cm}$, Jeromine $50.10 \mathrm{~cm}$, Pink Lady Rosy Glow $40.70 \mathrm{~cm}$ olarak tespit edilmiştir. Kısa dal uzunluğu en az olan çeşit Superchief $(39.63 \mathrm{~cm})$ iken kısa dalları en uzun olan çeşit Jeromine'dir $(50.10 \mathrm{~cm})$. Aralarındaki yaklaşık $11 \mathrm{~cm}$ 'lik fark istatistiki olarak önemli bulunmamıştır (Tablo 2).

Denemede fidanların orta dal uzunluğu sırasıyla şu şekilde ölçülmüştür: Scarlet $55.56 \mathrm{~cm}$, Superchief 63.06 cm, Jeromine 62.00 cm, Pink Lady Rosy Glow 52.10 cm. Orta dalı en kısa çeşit Pink Lady Rosy Glow $(52.10 \mathrm{~cm})$ 
Canan ve ark., Bolu İli Ekolojik Koşullarında Scarlet, Superchief, Jeromine, Pink Layd Rosy Glow Elma (Malus communis L.) Çeşitlerinin Adaptasyon Kabiliyetlerinin Belirlenmesi

iken en uzun çeşit Superchief $(63.06 \mathrm{~cm})$ olmuştur. Aralarındaki yaklaşık $11 \mathrm{~cm}$ 'lik fark istatistiki olarak önemli bulunmamıştır (Tablo 2).

Çalışmada yapılan ölçümlerde çeşitlerin uzun dal uzunluğu şu şekilde tespit edilmiştir: Scarlet $74.60 \mathrm{~cm}$ Superchief $91.99 \mathrm{~cm}$, Jeromine $77.10 \mathrm{~cm}$, Pink Lady Rosy Glow $59.10 \mathrm{~cm}$. En kısa uzun dal uzunluğuna sahip çeşit Pink Lady Rosy Glow $(59.10 \mathrm{~cm}$ ) iken en uzun çeşit Superchief $(91.99 \mathrm{~cm})$ olmuştur. Aralarındaki $32.89 \mathrm{~cm}$ 'lik fark istatistiki olarak önemli bulunmuştur (Tablo 2). Tallurto ve ark. (2008) MM106 anacı üzerine aşılı 5 yaşlı Pink Lady çeşidinde dal uzunluğunun $34.30 \mathrm{~cm}$ olduğunu bildirmiştir. Çalışmamızda elde edilen dal uzunluğu miktarı söz konusu araştırıcıların bildirdiği değerden yüksek bulunmuştur. Bu farklıı̆ın kültürel uygulamalardan kaynaklanabileceği ayrıca daha genç ağaçlarda dal uzunluğunun daha fazla olabileceği öngörülmektedir.

Çeşitlerin gövde çapı sırasıyla; Scarlet $5.45 \mathrm{~cm}$, Superchief $5.95 \mathrm{~cm}$, Jeromine $6.11 \mathrm{~m}$, Pink Lady Rosy Glow $6.72 \mathrm{~cm}$ olarak tespit edilmiştir. Gövde çapı en az olan çeşit Scarlet $(5.45 \mathrm{~cm})$ iken gövdesi en kalın olan çeşit Pink Lady Rosy Glow'dur $(6.72 \mathrm{~cm})$. Aralarındaki $1.27 \mathrm{~cm}$ 'lik fark istatistiki olarak önemli bulunmuştur (Tablo 2).

Denemede fidanların dal sayısı sırasıyla şu şekilde ölçülmüştür: Scarlet 7.40 adet, Superchief 3.67 adet, Jeromine 7.00 adet, Pink Lady Rosy Glow 7.00 adet. Dal sayısı en az çeşit Superchief (3.67 adet) iken en fazla olan çeşit Scarlet (7.40 adet) olmuştur. Aralarındaki yaklaşık 3.73 adet'lik fark istatistiki olarak önemli bulunmuştur (Tablo 2).

Çalışmada yapılan ölçümlerde çeşitlerin dal çapı şu şekilde tespit edilmiştir: Scarlet $3.30 \mathrm{~cm}$, Superchief 3.51 $\mathrm{cm}$, Jeromine $2.31 \mathrm{~cm}$, Pink Lady Rosy Glow $2.05 \mathrm{~cm}$. En az dal çapına sahip çeşit Pink Lady Rosy Glow $(2.05 \mathrm{~cm})$ iken en fazla dal çapına sahip çeşit Superchief $(3.51 \mathrm{~cm})$ olmuştur. Aralarındaki $1.46 \mathrm{~cm}$ 'lik fark istatistiki olarak önemli bulunmuştur (Tablo 2).

Çeşitlerin yaprak sayısı sırasıyla şu şekilde ölçülmüştür: Scarlet 88.30adet, Superchief 60.70 adet, Jeromine 97.00adet, Pink Lady Rosy Glow 77.10 adet. Yaprak sayısı en az çeşit Pink Lady Rosy Glow (77.10 adet) iken en fazla olan çeşit Jeromine (97.00 adet) olmuştur. Aralarındaki yaklaşık 20adet'lik fark istatistiki olarak önemli bulunmamıştır (Tablo 2).

Çeşitlerin yaprak uzunluğu sırasıyla Scarlet $6.30 \mathrm{~cm}$, Superchief $6.03 \mathrm{~cm}$, Jeromine $5.64 \mathrm{~cm}$, Pink Lady Rosy Glow $6.67 \mathrm{~cm}$ olarak tespit edilmiştir. Yaprak uzunluğu en kısa olan çeşit Jeromine $(5.64 \mathrm{~cm})$ iken yaprak uzunluğu en uzun olan çeşit Pink Lady Rosy Glow'dur $(6.67 \mathrm{~cm})$. Aralarındaki $1.03 \mathrm{~cm}$ 'lik fark istatistiki olarak önemli bulunmuştur (Tablo 2).

Çeşitlerin yaprak eni sırasıyla Scarlet $3.35 \mathrm{~cm}$, Superchief $3.74 \mathrm{~cm}$, Jeromine $3.70 \mathrm{~cm}$, Pink Lady Rosy Glow $4.12 \mathrm{~cm}$ olarak tespit edilmiştir. Yaprak uzunluğu en kısa olan çeşit Scarlet $(3.35 \mathrm{~cm})$ iken yaprak uzunluğu en uzun olan çeşit Pink Lady Rosy Glow'dur $(4.12 \mathrm{~cm})$. Aralarındaki $0.77 \mathrm{~cm}$ 'lik fark istatistiki olarak önemli bulunmamıştır (Tablo 2).

Çeşitlerin don zararı sırasıyla Scarlet \%59.70, Superchief \%43.00, Jeromine \%14.50, Pink Lady Rosy Glow \%16.70 olarak tespit edilmiştir. Don zararına en az maruz kalan çeşit Jeromine (\%14.50) iken en fazla don zararına maruz kalan çeşit Scarlet'dir (\%59.50). Aralarındaki \%45'lik fark istatistiki olarak önemli bulunmuştur (Tablo 2). Pink Lady Rosy Glow'da jeromine ile birlikte don zararına göreceli olarak daha az maruz kalan iki çeşitten ikincisi olmuştur (\%16.70).

Tablo 2. Elma çeşitlerinin fidan gelişim değerleri.

Table 2. Seedling growth values of apple cultivars.

\begin{tabular}{|c|c|c|c|c|c|}
\hline Özellikler & Scarlet & Superchief & Jeromine & Pink Lady- Rosy Glow & LSD (\%5) \\
\hline Ağaç Boyu (cm) & $122.80 \pm 16.68$ & $114.80 \pm 16.92$ & $135.80 \pm 8.48$ & $130.40 \pm 7.71$ & Ö.D \\
\hline Kısa Dal Uzunluğu (cm) & $48.44 \pm 7.59$ & $39.63 \pm 6.89$ & $50.10+6.19$ & $40.70 \pm 3.97$ & Ö.D. \\
\hline Orta Dal Uzunluğu (cm) & $55.56 \pm 6.57$ & $63.06 \pm 6.67$ & $62.00 \pm 7.23$ & $52.10 \pm 6.90$ & Ö.D. \\
\hline Uzun Dal Uzunluğu (cm) & $74.60 \pm 7.97 \mathrm{ab}$ & $91.99 \pm 10.27 \mathrm{a}$ & $77.10 \pm 8.57 \mathrm{ab}$ & $59.10 \pm 7.02 b$ & 24.49 \\
\hline Gövde Çapı (cm) & $5.45 \pm 0.23 b$ & $5.95 \pm 0.53 a b$ & $6.11 \pm 0.30 a b$ & $6.72 \pm 0.45 a$ & 1.12 \\
\hline Dal Sayısı (Adet) & $7.40 \pm 0.67 \mathrm{a}$ & $3.67 \pm 0.70 b$ & $7.00 \pm 0.75 a$ & $7.00 \pm 0.67 \mathrm{a}$ & 1.99 \\
\hline Dal Çapı (cm) & $3.30 \pm 0.29 a$ & $3.51 \pm 0.19 a$ & $2.31 \pm 0.17 b$ & $2.05 \pm 0.18 b$ & 0.61 \\
\hline Yaprak Sayısı (Adet) & $88.30 \pm 17.99$ & $60.70 \pm 16.58$ & $97.00 \pm 17.59$ & $77.10 \pm 5.52$ & Ö.D. \\
\hline Yaprak Uzunluğu (cm) & $6.30 \pm 0.43 a b$ & $6.03 \pm 0.28 a b$ & $5.64 \pm 0.25 b$ & $6.67 \pm 0.40 a$ & 0.99 \\
\hline Yaprak Eni (cm) & $3.35 \pm 0.31$ & $3.74 \pm 0.33$ & $3.70 \pm 0.23$ & $4.12 \pm 0.27$ & Ö.D. \\
\hline Don Zararı (\%) & $59.50 \pm 7.17 \mathrm{a}$ & $43.00 \pm 8.73 \mathrm{a}$ & $14.50 \pm 5.29 b$ & $16.70 \pm 3.99 b$ & 18.78 \\
\hline
\end{tabular}

Çalışmada incelenen kriterler arasında pozitif ve negatif yönlü kuvvetli ilişkiler tespit edilmiştir (Tablo 3). Varlığı tespit edilen ancak kuvveti daha düşük (\%95) olan önemli ilişkilerde şu şekildedir: Uzun dalın uzunluğu arttıkça kısa dalında uzunluğu artmaktadır. Ağaç boyu arttıkça dal sayısı da artmaktadır. Dal sayısı arttıkça uzun 
dalın uzunluğu azalmaktadır. Dal çapı arttıkça uzun dal ve orta dal daha fazla uzamaktadır. Yaprak sayısı arttıkça ağaç boyu kısa dal uzunluğu artmaktadır. Dal sayısı arttıkça yaprakların eni azalmaktadır. Dal çapı arttıkça don zararı da artmaktadır (Tablo3). İstatistiki olarak önemli olmasa da don zararı ile ilgili şu ilişkilerde mevcuttur: Don zararı; ağaç boyu, kısa-orta dal uzunlukları, gövde çapı ve dal sayısı ile ters orantılıdır (Tablo 3).

Tablo 3. Elma çeşitlerinde incelenen parametrelere ait korelasyon değerleri.

Table 3. Correlation coefficients of studied parameters of apple cultivars.

\begin{tabular}{|c|c|c|c|c|c|c|c|c|c|c|c|}
\hline & $A B$ & KDU & ODU & UDU & GÇ & DS & DÇ & YS & YU & YE & DZ \\
\hline AB & 1.00 & 0.10 & 0.05 & -0.09 & 0.12 & 0.33* & 0.03 & 0.35 & -0.05 & -0.04 & -0.20 \\
\hline KDU & & 1.00 & $0.74^{* *}$ & $0.38^{*}$ & 0.17 & 0.23 & 0.13 & 0.32 & -0.06 & -0.19 & -0.15 \\
\hline ODU & & & 1.00 & $0.73^{* *}$ & 0.25 & -0.09 & $0.32^{*}$ & 0.10 & -0.01 & 0.13 & -0.06 \\
\hline UDU & & & & 1.00 & 0.17 & $-0.41^{*}$ & $0.47^{*}$ & -0.15 & 0.10 & 0.18 & 0.18 \\
\hline GÇ & & & & & 1.00 & 0.13 & 0.11 & 0.22 & 0.08 & 0.14 & -0.24 \\
\hline DS & & & & & & 1.00 & -0.25 & $0.64^{* *}$ & -0.25 & $-0.36^{*}$ & -0.24 \\
\hline DÇ & & & & & & & 1.00 & 0.15 & 0.09 & 0.09 & $0.36^{*}$ \\
\hline YS & & & & & & & & 1.00 & -0.06 & -0.06 & $-0.42^{*}$ \\
\hline YU & & & & & & & & & 1.00 & $0.66^{* *}$ & 0.05 \\
\hline YE & & & & & & & & & & 1.00 & -0.08 \\
\hline DZ & & & & & & & & & & & 1.00 \\
\hline
\end{tabular}

* 0.05 düzeyinde önemlidir. ${ }^{*} 0.01$ düzeyinde önemlidir.

AB:Ağaç boyu, KDU:Kısa dal uzunluğu, ODU: Orta dal uzunluğu, UDU: Uzun dal uzunluğu, GÇ: Gövde çapı, DS: Dal sayısı, DÇ: Dal çapı, YS: Yaprak sayısı, YU: Yaprak uzun, YE: Yaprak eni, DZ: Don Zararı

Yapılan temel bileşen analizi (TBA) sonucunda Pink Lady gövde çapı ve yaprak eni açısından öne çıkarken, Jeromine'nin yaprak sayısı ve dal sayısı bakımından öne çıktığı görülmektedir. TBA'da görüldüğü üzere Scarlet ve Jeromin çeşidi biribiriyle pozitif ilişki gösterirken, diğer çeşit ilişkilerinin tamamı negatif olarak görülmektedir. Dal uzunlukları ile yaprak eni ve boyu değerlerinin negatif ilişkili olduğu görülmektedir (Şekil 2)

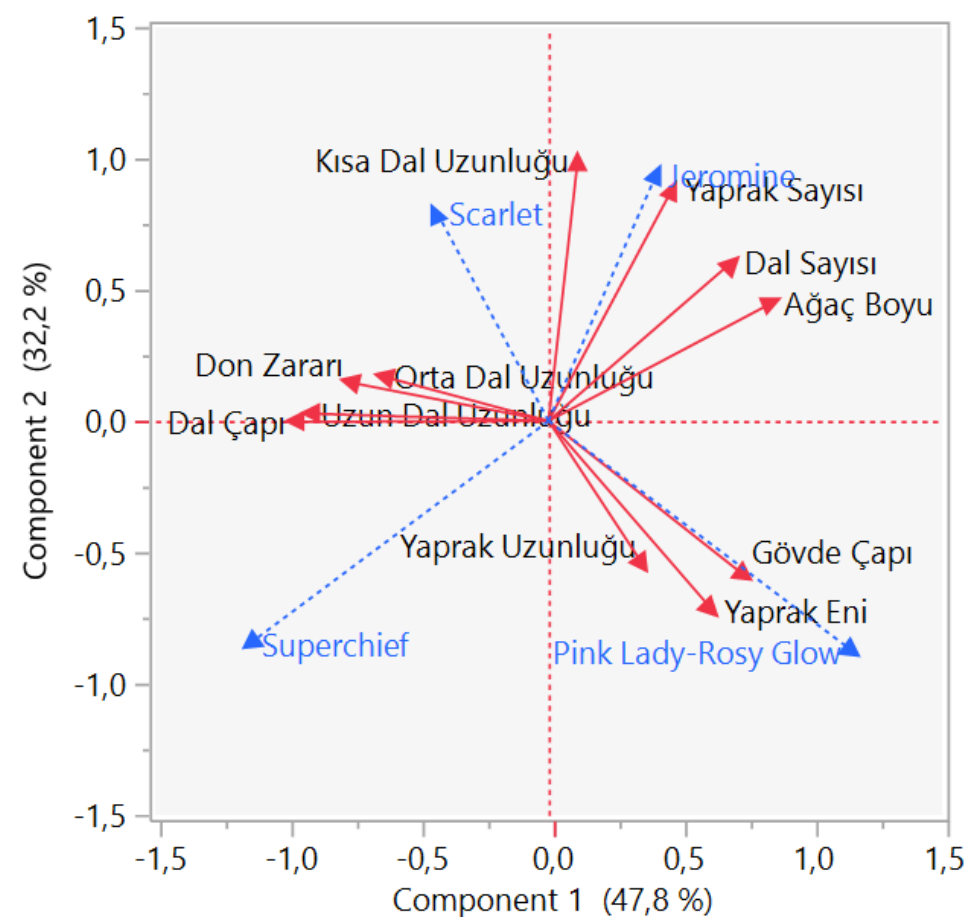

Şekil 2. Elma çeşitlerinde fidan gelişim parametrelerinin TBA analiziyle değerlendirilmesi.

Figure 2. Evaluation of seedling growth parameters of apple cultivars with PCA analysis.

\section{SONUÇ}

Bolu ili için meyveciliği sınırlandıran en önemli özellik çeşitlerin don zararına hassasiyeti olarak kabul edilmektedir.

Sırasıyla Jeromine ve Pink Lady Rosy Glow çeşitleri hızlı gelişimi (uzun ağaç boyu), birçok gelişim özellikleri açısından diğer çeşitlerden iyi olması ve don zararına göreceli olarak daha dayanıklı olmaları nedeniyle Bolu'da elma yetiştirmek isteyenlere tavsiye edilebilmektedir. 
Canan ve ark., Bolu İli Ekolojik Koşullarında Scarlet, Superchief, Jeromine, Pink Layd Rosy Glow Elma (Malus communis L.) Çeşitlerinin Adaptasyon Kabiliyetlerinin Belirlenmesi

Adaptasyon çalışmaları uzun yıllar takip edilmesi gereken çalışmalardır. Bizim çalışmamız yeni tesis edilecek bahçelerde fidan aşamasında ilk birkaç yıl içerisinde Bolu İklim koşullarında gerçekleşebilecek durumları ortaya koyması ve fikir vermesi açısından önemlidir. Bolu sonbahar erken ve ilkbahar geç donlarının çok etkili olduğu, kış koşullarının birçok meyve türü için kısa ve vejetasyon süresinin oldukça kısa olduğu bir iklime sahiptir. Çalışmanın yeni ve farklı tür ve çeşitleri içerecek şekilde genişletilmesi faydalı olacaktır.

\section{ÇIKAR ÇATIŞMASI}

Yazarlar arasında herhangi bir çıkar çatışması bulunmamaktadır.

\section{YAZAR KATKISI}

İhsan CANAN ve Muttalip GÜNDOĞDU çalışmanın planlanması ve uygulamasında görev almıştır. Akgül TAŞ, insan CANAN ve Muttalip GÜNDOĞDU verilerin işlenmesi ve makalenin yazımında görev almıştır.

\section{TEŞEKKÜR}

Bu çalışma Bolu Abant İzzet Baysal Üniversitesi Bilimsel Araştırma Projeleri birimince 2016.10.05.980 no'lu proje ile desteklenmiştir. Söz konusu üniversite ve birime destekleri için teşekkür ederiz.

\section{KAYNAKLAR}

Ağlar, E., \& Öztürk, B. (2018). Hasat öncesi metil jasmonat uygulamalarının soğukta muhafaza süresince Fuji elmasının meyve kalitesi üzerine etkisi. Uluslararası Tarım ve Yaban Hayatı Bilimleri Dergisi, 4(1), 13-19.

Bolat, İ. (2011). Erzincan Bahçe Kültürleri Araştırma Enstitüsü fidanlık arazisinde bazı meyve türlerinde çöğür gelişiminin incelenmesi üzerine bir araştırma. Atatürk Üniversitesi Ziraat Fakültesi Dergisi, 25(1), 67-77.

Çorumlu, M. S. (2010). Çorum ili iskilip ilçesinde yetiştirilen bazı yerel elma (Malus Communis L.) çeşitlerinin fenolojik ve pomolojik özelliklerinin belirlenmesi. Yüksek Lisans Tezi, Ordu Üniversitesi, Fen Bilimleri Enstitüsü, Ordu.

Dziubiak, M. (2004). Collection of the genus Malus Mill. in the botanical garden of the Polish Academy of Sciences in Warsaw. Journal of Fruit and Ornamental Plant Research, 12,121-128.

Edizer, Y., \& Bekar, T. (2007). Tokat merkez ilçede yetiştirilen bazı yerel elma (Malus communis L.) çeşitlerinin fenolojik ve pomolojik özelliklerinin belirlenmesi. Gaziosmanpaşa Üniversitesi Ziraat Fakültesi Dergisi, 24(1), 1-8.

Ercisli, S. (2004). A short review of the fruit germplasm resources of Turkey. Genetic Resources and Crop Evolution, 51(4), 419435.

Eskimez, İ., Polat, M., \& Mertoğlu, K. (2020). M9 anacı üzerine aşılı Arapkızı, Jonagold ve Fuji Kiku elma (Malus domestica Borkh.) çeşitlerinin Isparta ekolojik koşullarında fenolojik ve fiziko-kimyasal özellikleri. Uluslararası Tarım ve Yaban Hayatı Bilimleri Dergisi, 6(2), 152-159.

FAO. (2019). Food and agriculture data. http://www.fao.org/statistics/en/ Erişim tarihi: 15 Mayıs 2019.

Güleryüz, M., \& Ercişli, S. (1995). Kağızman ilçesinde yetiştirilen mahalli elma çeşitleri üzerinde biyolojik ve pomolojik araştırmalar. Atatürk Üniversitesi Ziraat Fakültesi Dergisi, 26(2), 183-193.

MGM. (2021). illere ait mevsim normalleri (1991-2020). https://www.mgm.gov.tr/veridegerlendirme/il-ve-ilceleristatistik.aspx?m=BOLU Erişim tarihi:19 Mart 2021.

Özbek, S. (1978). Özel meyvecilik. Çukurova Üniversitesi Ziraat Fakültesi Yayınları, 128, 392-483.

Özongun, Ş., Dolunay, E. M., Pektaş, M., Öztürk, G., Çalhan, Ö., \& Atay, E. (2016). Farklı klon anaçları üzerinde bazı elma çeşitlerinin verim ve kalite değişimleri. Ege Üniversitesi Ziraat Fakültesi Dergisi, 53(1), 35-42.

Öztürk, F. P., Karamürsel, D., \& Emre, M. (2011). Elma Kültürü: Dünyada Elmanın Ekonomik Yeri. Eğirdir.

Sönmez, F., Gülser, F., Karaca, S., \& Gökkaya, T. (2018). Bolu Abant İzzet Baysal Üniversitesi araştırma alanları topraklarının bazı fiziksel ve kimyasal özelliklerinin belirlenmesi. Uluslararası Tarım ve Yaban Hayatı Bilimleri Dergisi, 4(1), 68-78.

Talluto, G., Farina, V, Volpe, G., \& Bianco, R. L. (2008). Effects of partial rootzone drying and rootstock vigour on growth and fruit quality of 'Pink Lady'apple trees in Mediterranean environments. Australian Journal of Agricultural Research, 59(9), 785-794.

Taş, A., Güler, E., Canan, İ., \& Gündoğdu, M. (2019). Bazı erik çeşitlerinin fidan gelişim performanslarının belirlenmesi. Hasat Uluslararası Tarım ve Orman Kongresi, Ankara. 
Canan ve ark., Bolu Ili Ekolojik Koşullarında Scarlet, Superchief, Jeromine, Pink Layd Rosy Glow Elma (Malus communis L.) Çeşitlerinin Adaptasyon Kabiliyetlerinin Belirlenmesi

Team, R. C. (2013). R: A language and environment for statistical computing. R Foundation for Statistical Computing, Vienna, Austria. URL: http://www.R-project.org/ Erişim tarihi:19 Mart 2021.

TÜiK. (2019). Bitkisel üretim istatistikleri. http://tuik.gov.tr/Start.do Erişim tarihi: 15 Mayıs 2019 